\title{
The Ecosystem-Based Management System: A Formal Tool for the Management of the Marine Environment
}

\author{
Rafael Sardá. Departament of Operational Marine Sciences and Sustainability. \\ CEAB-CSIC.Spain.sarda@ceab.csic.es \\ Amy Diedrich.OceanBit. Spain. amy.diedrich@uib.es \\ Joaquin Tintoré. OceanBit.Spain. jitintore@uib.es \\ Roland Cormier. Departament of Fisheries and Oceans. Canada.
}

Roland.Cormier@dfo-mpo.gc.ca

\begin{abstract}
The new marine policy of the European Union (Marine Strategy Directive and the Integrated Maritime Policy) respond to the introduction of the concept of Sustainable Development into the management of the marine environment. The understanding and commitment of the application of such a concept to Europe's Seas is critical for the future and requires new guidelines and tools to assist their implementation. International agreement has recognised the need to establish the management of oceans and coasts based on the Ecosystem approach and its associated principles. To reach this objective, we are proposing a structured system of procedures and tools, here called Ecosystem-Based Management System (EBMS), aimed at implementing the Ecosystem approach at different spatial and administrative scales. This managerial system should be implemented within effective governance structures designed to uphold the modern principles of environmental management.
\end{abstract}

Keywords: Ecosystem Approach. Management System. European Union.

\section{Introduction}

The achievement of Good Environmental Status (GES) and sustainable use of marine ecosystems are the primary objectives of the new Marine Environmental Policy of the European Union (Marine Strategy Framework Directive (MSFD) and the Integrated Maritime Policy (IMP)). This new policy is aimed towards a common vision and a holistic, integrated approach to the management of the marine environment using the Ecosystem Approach as its basic frame of reference. In order to implement this approach, a shift is needed from disharmonious, sector-oriented managerial approaches to a more holistic process-oriented management system. As a consequence, it becomes necessary to develop comprehensive, science-based practical guidelines and tools to assist with the implementation of this new policy and environmental legislation proposed by the European Union.

In recent years, the concept of the Ecosystem Approach has gained respect among academics as a positive contribution towards solving the problem of the management of environmental public goods, and has become increasingly cited and used in the academic literature as well as in policy regulation instruments. The Ecosystem Approach is a strategy for the integrated management of land, water and living resources

This is an Open Access article distributed under the terms of the Creative Commons Attribution-Noncommercial License 3.0, which permits unrestricted use, distribution, and reproduction in any noncommercial medium, provided the original work is properly cited. 
that promotes conservation and sustainable use in an equitable way. It is the primary framework for action under the Convention on Biological Diversity. Following the Convention, the Ecosystem approach is based on the application of appropriate scientific methodologies focused on levels of biological organization which encompass the essential processes, functions and interactions among organisms and their environment. It recognizes that humans, with their cultural diversity, are an integral component of ecosystem (http://www.cbd.int/).

Prior to the emergence of the Ecosystem Approach and other integrated approaches to environmental management, ecological and anthropogenic systems were generally managed separately, with a different set of objectives and associated management frameworks. It is now recognized that human activity and the ecosystems in which they occur cannot be separated and should be managed as a whole. This forms the fundamental basis for the application of the Ecosystem Approach and has resulted in the emergence of the concept of social-ecological systems. Social-ecological systems reflect the inextricable link between society and ecology. Bearing in mind the fact that the MSFD defines the overall objective of Good Environmental Status (GES) in largely ecological terms, where the IMP is more focused on human aspects of marine management, the Ecosystem Approach (referred to as Ecosystem-Based ManagementEBM in many of its policy applications) is a valuable concept that draws together the objectives of both policies. Currently, the concepts of the Ecosystem Approach and EBM are often not fully differentiated, which may be viewed as a reflection of the absence of a clearly defined framework for implementation.

The concept of the Ecosystem Approach has developed into a series of principles by various institutions, the most notable are the Malawi Principles adopted under the Convention on Biological Diversity (CBD, 1998). These principles should be applied through the implementation of an Ecosystem-Based Management-EBM. The purpose of this paper is to introduce an operational framework, a systematic process able to translate the Ecosystem Approach concept or its Ecosystem-Based Management version into tangible management practices, this framework constitutes the EcosystemBased Management System (EBMS).

\section{The Ecosystem-Based Management System (EBMS)}

Management is about making decisions. In this context, management of environmental public goods and services is about making the best decisions for societies and for the effective functioning of these public goods. The Ecosystem-Based Management System (EBMS) framework has been designed to combine classical Environmental Management System (EMS) theory with the Ecosystem-Based Management (EBM) principles. Environmental Management Systems (EMS) are useful frameworks through which organizations can reduce their environmental impact, improve their environmental performance, and provide relevant information to the public and other interested parties. Ecosystem-Based Management (EBM), on the other hand, represents a policy framework for the application of the Ecosystem Approach concept (ELI, 2009). Used in conjunction with each other, EMS may be viewed as a useful tool for delivering the Ecosystem Approach which, in turn, may be expressed through the implementation of EBM. We use the term Ecosystem-Based Management System (EBMS) to define a 
systematic approach that links the EMS tool with the EBM framework. The EBMS is intended then to provide a systematic approach for the principles of the Ecosystem Approach by introducing them into a clear, familiar, managerial framework.

The Ecosystem Approach considers ecosystems to be comprised of human and ecological components (i.e. social-ecological systems), where traditional environmental management, and hence Environmental Management Systems (EMS), is more focused on ecological systems, with human activities being an external pressure upon these systems. In order to account for this shift in approaches to environmental management, we have adapted the different elements and clauses associated with the traditional EMS framework (using the ISO 14001 as example to be the most well known used one) to reflect an ecosystem orientated approach. Part of this adaptation includes some changes to the general terminology associated with EMS as it applies to EBMS

The basic design of the Ecosystem-Based Management System (EBMS) can be divided into three components (a three pillar structure: the managerial pillar, an information pillar, and a participatory pillar). The managerial pillar is the basis of the system, the one that resembles a formal Environmental Management System (EMS), while the information pillar and the participatory pillar provide necessary inputs for the functioning and performance of the managerial system, as well as to facilitate a wider use of sustainable development principles such as integration, adaptability, transparency or participation. Figure 1. shows how the three different pillars of the EBMS work together.

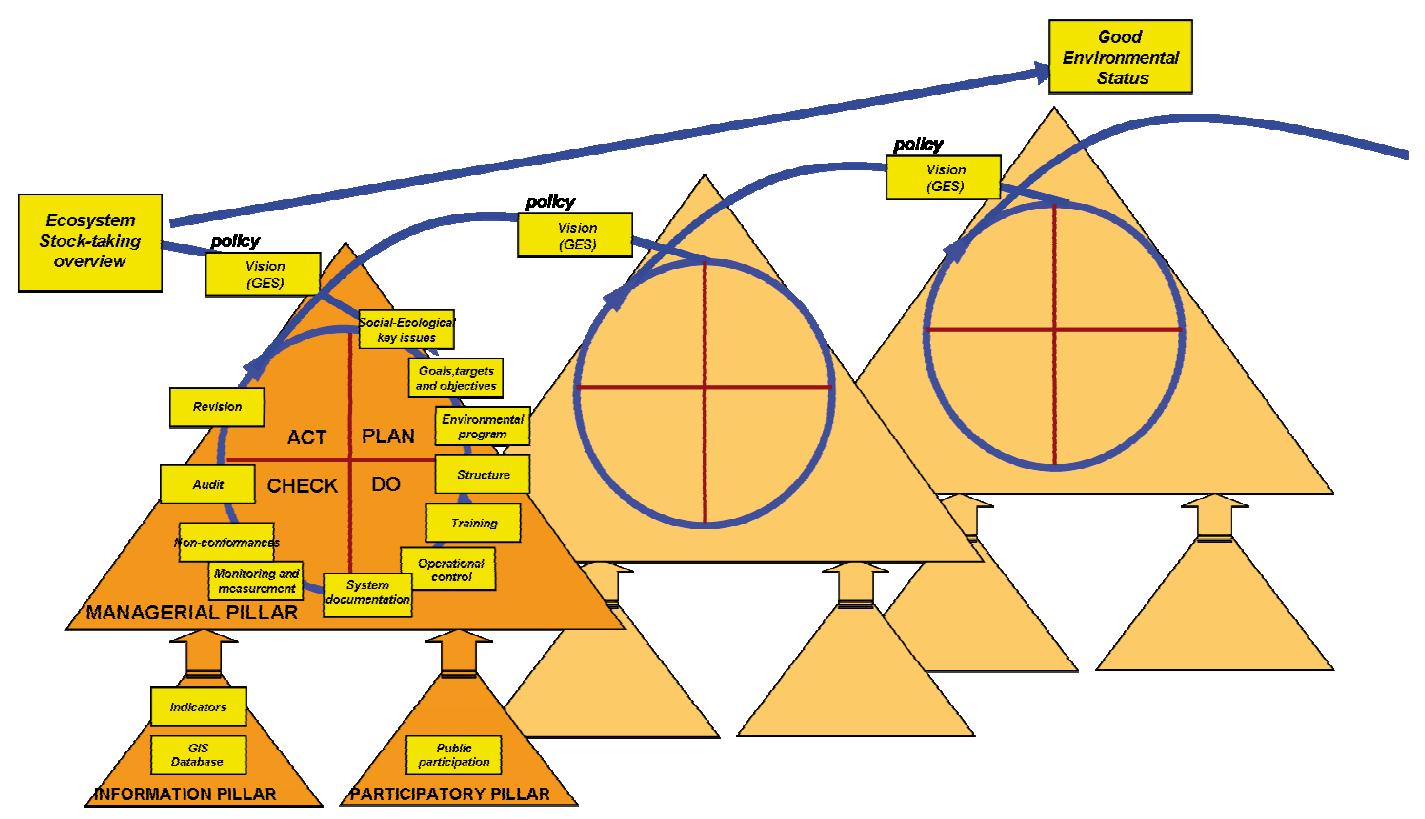

Figure-1. The Ecosystem-Based Management System structure

The conceptual thinking underpinning the managerial pillar is the policy cycle assessment developed interalia by the Joint Group of Experts on the Scientific Aspects of Marine Environmental Protection (GESAMP, 1996) This policy cycle follows the classical PDCA (Plan-Do-Check-Act) managerial scheme, the so-called Deming cycle (Deming, 
1986), a continuous quality improvement model consisting of a logical sequence of four repetitive steps that uses an iterative logic for the continuous improvement and adaptation of the systems under management. The information pillar is designed to assist the managerial pillar with user-friendly tools than can facilitate the flow of information into the decision making process, while the participatory pillar in the Ecosystem-Based Management System (EBMS) should seek to enhance communication with stakeholders and to service needs for capacity building.

Based on the scheme presented in Fig.1, the key components of an Ecosystem-Based Management System (EBMS) would be:

\subsection{The policy element. Baseline assessment and goal setting.}

The new marine policy of the European Union (MSFD) establishes a framework for the development of marine strategies designed to achieve Good Environmental Status (GES) in the marine environment by the year 2021. As it has been indicated widely, central to Ecosystem-Based Management (EBM) is the need to develop a common vision of a healthy and resilient marine environment that considers the ecosystem, society and the economy; as well as a plan of action to achieve that vision (ELI, 2009). In the case of the marine environment, and in the European zone, GES should be the desired vision for every case under management. Then, In order to achieve this, a necessary step is the definition of a mission statement which describes the GES and its roadmap to reach it and/or to maintain it. This will require a baseline assessment of the social-ecological status of the region/area/problem under management, through the implementation of an Ecosystem Overview and Assessment Report.

\subsection{The planning phase.}

The area of planning will perhaps be the most challenging. Planning should address the significant risks that could impede achievement of attaining GES. These risks fall basically into two main groups: 1) those derived from external pressures and/or events that can separate future and/or present environmental states from the desired ones, and, 2) those related to an evaluation of the capacity of the region to provide ecosystem services, based on the GES indicators. Historically, decision-making at this level had been largely sectoral and more judgmental than analytical. Correct selection of the significant social-ecological key aspects could favour programs intended to reduce negative effects on our move towards GES. The Ecosystem-Based Management System (EBMS) is intended to work with a Decision making tool (DEMA) that uses a Risk Analysis framework (FAO, 1995) to select priority actions.

\subsection{Implementation and operation}

The planning phase ends with a final description of objectives and targets associated with several programmes, defined in a precise Integrated Management Plan, and aimed towards the continual improvement of a cyclical process intended to reach GES. The Effective Governance Structure (EGS) created to support and implement the EBMS must ensure that its organization is going to be capable of achieving its objectives through the appropriate allocation of people, resources, systems, strategy, and structure. Here, two elements become really important to ensure the successful appli- 
cation of the implementation and operation stage; the operational control of the activities (i.e. monitoring of programme effectiveness), and the capacity of the personnel.

\subsection{Checking and corrective action}

The checking and corrective action stage is based on the development of compliance monitoring programs, including monitoring of program activities, compliance verification and audits. At this particular stage, the system should be able to analyse the level of conformity with successful outputs of associated programs and the effectiveness of these programs in achieving the vision proposed for the management system. The audit should determine the level of conformity in the way we have reached our objectives as well as the effectiveness of our actions in protecting the marine environment under management.

\subsection{The review phase}

During the previous policy phase, a particular vision was developed to achieve GES, associated with the mission statement. Based on that, a series of programs were planned, intended to reach several goals and targets during a particular reference period. The management review should go through the information, records, data and documentation that have been created during this cycle to evaluate the successful application of the performed activities and measures. At this phase, the review of the activities done, the new scientific information, and the necessary tradeoffs should allow for a revision of the vision that will constitute the basic aim to develop new objectives, targets, and programmes for the next management cycle.

\section{Future applications of the the Ecosystem-Based Management System (EBMS)}

Today's management of European seas is heavily determined by jurisdictional boundaries. When national jurisdictions are considered, different political administrations address managerial aspects in their coastal waters sometimes with opposing objectives and strategies. This division of competences makes marine management issues extremely haphazard and has contributed to discord in the development of coastal and offshore areas. Taking into account this complexity, the new Ecosystem-Based Management System (EBM) must evolve in parallel with a more integrated, spatially coordinated, Effective Governance Structure (EGS) designed to uphold the modern principles of environmental management (Olsen et al., 2009).

Good Environmental Status (GES) is ultimately determined by the needs of society. It is unlikely that goals based on a return to pristine conditions could be achievable so the process has to be forward looking and relies on a dialogue with stakeholders about what is feasible in the future and how this relates to the maintenance of ecosystem services. It is also necessary to reach a societal consensus of the vision desired for the future, a vision which should be directed towards GES. The EBMS can only be effective if it is easily understood by regulated parties and the public, so it becomes necessary to delineate, through effective communication, a comprehensive framework that clearly defines the appropriate roles for different levels of government, the private sector and citizens promoting effective partnerships for managing the marine ecosystem services, and strategic tools for policy implementation. 
New integrated management programmes, systematic approaches combining effective governance structures (EGS) with formal managerial systems (EBMS) can constitute an invaluable opportunity to learn from past practices, develop new skills, gain fresh insights and lead the way in which future management of the seas should be done. In Canada, a new legislative and policy framework to modernize oceans management is actually in place (Oceans Act-1996; Canada's Oceans Strategy-2002) (DFO, 2005). Since them, the Department of Fisheries and Oceans of Canada have been working with the development of several tools (ecosystem science and monitoring, ecosystem health framework, social, cultural and economic analytical practices,) within the context of risk analysis and decision-making support to implement the Strategy. Using the lessons learned by the work done by the Canadian Administration developing Effective Governance Structures (EGS), we could see of their developments can be accommodated into a formal systemic approach, something that could resemble an EcosystemBased Management System (EBMS) for the management of the marine environment. In this way the EBMS could be intended as a standard application make of different tools and used in a systemic way that can facilitate the introduction of today's required new instrument to manage the marine domain.

\section{References}

Convention on Biological Diversity (CBD). 1998. Report of the workshop on Ecosystem Approach. 15 pp.

Deming E.W., 1986. Out of the Crisis. MIT Centre for Advanced Engineering Study.

Department of Fisheries and Oceans (DFO). 2005. Canada's Oceans Action Plan: for present and future generations. $20 \mathrm{pp}$.

Environmental Law Institute (ELI). 2009. Ocean and Coastal Ecosystem-Based Management: implementation handbook. Washington. 159 pp.

Food and Agriculture Organization of the United nations (FAO). 1995. Application of Risk Analysis to Food Standard issues. Report of the Joint FAO/WHO experts. 39 pp.

GESAMP. 1996. The contribution of Science to Integrated Coastal Management, Reports and Studies no 61. Food and Agriculture UN. Rome.

Olsen S,B., Page G.G. and Ochoa E., 2009. The Analysis of Governance to Ecosystem Change: A handbook for assembling a baseline. LOICZ reports and studies, no 34 . GKSS Research centre, Geesthacht. 87 pp.

\section{Acknowledgements}

This paper is a contribution of the European Community's Seventh Framework Research Project KNOWSEAS (Knowledge-based Sustainable Management for Europe's Seas; http://www.knowseas.org ), working under grant agreement 226675. 